\title{
Incompatibilidade de enxertia induz aumento da suscetibilidade de cultivares de pessegueiro à Xanthomonas arboricola pv. Pruni
}

\author{
Graft incompatibility induces susceptibility increase of peach cultivars to \\ Xanthomonas arboricola pv. Pruni
}

\author{
Ivan dos Santos Pereira' Luis Eduardo Corrêa Antunes ${ }^{\text {II }}$ \\ Luciano Picolotto' ${ }^{\text {III }}$ José Carlos Fachinello ${ }^{\text {IV }}$
}

\section{RESUMO}

\begin{abstract}
Oobjetivo deste trabalho foi avaliar a compatibilidade de enxertia, a suscetibilidade à bacteriose e a frutificação de oito combinações, assim como, a influência da compatibilidade sobre a severidade da doença e a frutificação do pessegueiro. Oexperimento foi realizado ao nível de campo, sob infecção natural da bactéria, no Centro Agropecuário da Palma, pertencente à FAEM/UFPel, em Capão do Leão-RS. Foram avaliadas as combinações entre as cultivares 'Chimarrita'e 'Maciel'e os porta-enxertos 'Aldrighi', 'Capdeboscq', 'Tsukuba 1'e 'Umezeiro'. O pomar foi implantado em delineamento experimental de blocos casualizados com quatro repetições, sendo cada unidade experimental composta de cinco plantas. Foi avaliada, a compatibilidade de enxertia, o diâmetro do caule, a severidade de dano e o índice de doença, a área foliar e a frutificação. As combinações entre as cultivares 'Chimarrita' $e$ 'Maciel' e o porta-enxerto 'Umezeiro', apresentaram menor compatibilidade de enxertia, maior severidade de dano e indice de bacteriose, além de menor frutificação que as demais. Os resultados obtidos possibilitaram concluir que as combinações 'Chimarrita'/'Umezeiro'e 'Maciel'/'Umezeiro'são incompativeis, além de, mais suscetiveis à bacteriose e menos produtivas, comparadas às demais. Pode-se dizer também, que a incompatibilidade de enxertia induz maior suscetibilidade das plantas à infecção por bacteriose, resultando em maior severidade da doença e menor frutificação.
\end{abstract}

Palavras-chave: Prunus, bacteriose, incompatibilidade de enxertia, porta-enxerto.

\section{ABSTRACT}

The objective of this study was to evaluate the graft compatibility, susceptibility to bacterial leaf spot and fruiting on eight combinations, as well as the influence of graft compatibility in the severity of the disease and fruiting. The research was conducted at the field under natural bacterial infection, in the Agricultural Center of Palma, belonging to the FAEM/UFPel, in Capão do Leão-RS. It was evaluated the combinations composed by grafting among the 'Chimarrita' and 'Maciel' cultivars and the rootstocks 'Aldrighi', 'Capdeboscq', 'Tsukuba 1' and 'Umezeiro'. The orchard was implanted in a randomized block design with four replications, each experimental unit composed of five plants. The graft compatibility, stem diameter, injury severity, disease index, leaf area and fruiting were evaluated. The combinations between 'Chimarrita' and 'Maciel' cultivars and 'Umezeiro' rootstocks showed lower graft compatibility, highest injury severity, disease index, as well as, lower fruiting. The results obtained allow to conclude that 'Chimarrita'/'Umezeiro' and 'Maciel'/'Umezeiro' combinations are incompatibles, more susceptible to bacterial leaf spot and less productive compared to the others. Furthermore, the graft incompatibility induces higher susceptibility of plants to bacterial leaf spot infection, resulting in greater disease severity and lower fruiting.

Key words: Prunus, bacterial leaf spot, graft incompatibility, rootstock.

\section{INTRODUÇÃO}

A enxertia é uma forma de propagação assexuada na qual se colocam em contato duas porções de tecido vegetal, de tal maneira que se unam e posteriormente se desenvolvam, originando uma nova planta (FACHINELLO et al., 2005). Geralmente os dois indivíduos que compõem um enxerto pertencem à mesma espécie botânica ou

IPrograma de Pós-doutorado CAPES-Embrapa, Embrapa Clima Temperado, 96010-971, Pelotas, RS, Brasil. E-mail: ivanspereira@gmail.com. Autor para correspondência.

IIDepartamento de Fruticultura, Embrapa Clima Temperado, Pelotas, RS, Brasil.

IIIPrograma de Pós-doutorado PNPD/Capes, Departamento de Fruticultura, Universidade Federal da Fronteira Sul (UFFS), Erechim, RS, Brasil.

${ }^{\text {IV }}$ Departamento de Fitotecnia, Universidade Federal de Pelotas (UFPEL), Pelotas, RS, Brasil. 
a espécies muito próximas dentro de um gênero (ERREA, 1991).

Atualmente, é cada vez mais frequente o uso de porta-enxertos pertencentes a espécies distintas da cultivar, com o objetivo de obter-se uma série de vantagens, como: ser resistente a doenças e pragas do solo, induzir vigor adequado ao pomar, induzir precocidade e ser eficiente na produção de frutas de qualidade. Porém, a combinação de indivíduos geneticamente diferentes pode resultar em problemas de compatibilidade (HARTMANN et al., 2002). A incompatibilidade de enxertia é a ausência de desenvolvimento normal dos tecidos no ponto de enxertia, resultando em feixes vasculares não completamente lignificados, que provocam uma interrupção da continuidade vascular e cambial, com consequentes problemas físicos à união do enxerto (MOSSE, 1958). Tal fenômeno pode acarretar uma série de distúrbios metabólicos na planta, que se refletem no seu crescimento e desenvolvimento. Neste trabalho, foram estudados seus efeitos sobre a suscetibilidade à bacteriose e à frutificação.

A bacteriose foliar, causada por Xanthomonas arboricola pv. Pruni, é uma das mais importantes doenças do pessegueiro [Prunus persica (L.) Batsch] no Brasil e no mundo (MEDEIROS et al., 2011). Nas folhas, seus sintomas são manchas angulares de $1 \mathrm{a} 3 \mathrm{~mm}$, de aspecto aquoso, com halo amarelado. As manchas progridem aumentando de tamanho e formando uma necrose de coloração púrpura ou preta, que, por fim, se desprende do limbo foliar, deixando a folha perfurada (MAY DE MIO et al., 2004).

Essa doença pode ocorrer em qualquer período do ciclo do pessegueiro, sendo favorecida por alta umidade ou chuvas e temperaturas amenas, sobrevivendo no inverno nos cancros nos ramos, principalmente (FORTES \& MARTINS, 1998). Os métodos de controle estão limitados à aplicação de produtos a base de cobre e práticas como desinfecção de ferramentas, adubação equilibrada e instalação de quebra-ventos. No entanto, a forma de controle ideal seria a utilização de cultivares resistentes.

Diante dessa dificuldade, alternativas para a redução dos danos estão sendo pesquisadas e, dentro desse contexto, o efeito do porta-enxerto sobre a resistência da cultivar pode ser um método viável. Alguns pesquisadores relatam o efeito do portaenxerto sobre a capacidade da cultivar em aumentar ou diminuir a sua suscetibilidade a diversas doenças (CARLUCCI et al., 2004; LOUWS et al., 2010).

O objetivo deste trabalho foi avaliar a compatibilidade de enxertia, a suscetibilidade à bacteriose e a frutificação das oito combinações estudadas. Ainda, avaliar a influência da compatibilidade sobre a severidade da doença e a frutificação.

\section{MATERIAL E MÉTODOS}

O experimento foi realizado ao nível de campo, sob infecção natural da bactéria, no Centro Agropecuário da Palma, pertencente à FAEM/ UFPel/RS. O pomar foi implantado em agosto de 2008, com uma densidade de 1.333 plantas por hectare em espaçamento $5 \times 1,5 \mathrm{~m}$, conduzidas em sistema ípsilon (Y).

O delineamento experimental foi de blocos casualizados com quatro repetições, sendo cada unidade experimental composta de cinco plantas. As cultivares 'Chimarrita' e 'Maciel' foram enxertadas sobre os porta-enxertos 'Aldrighi', 'Capdeboscq', 'Tsukuba 1' e 'Umezeiro', totalizando oito combinações.

As avaliações realizadas foram: compatibilidade de enxertia, diâmetro do caule ( $\mathrm{mm}$ ) na cultivar no porta-enxerto e no ponto de enxertia, avaliação de dano por bacteriose, causada pela bactéria Xanthomonas arboricola pv. pruni, nas folhas, índice de doença e frutificação.

Acompatibilidade de enxertia foi avaliada por dois métodos distintos, avaliação anatômica da união do enxerto e índice de compatibilidade e campo (ICC). No primeiro método, foi realizada a análise anatômica da região de união dos enxertos, conforme MOSSE \& HERRERO (1951). Essa avaliação classifica a união em cinco classes (A, B, $\mathrm{C}, \mathrm{D}$ e $\mathrm{E}$ ), que correspondem aos seguintes níveis de compatibilidade: A- união perfeita; B- boa união; C- união com descontinuidade na casca; Dunião com descontinuidade do lenho; e E- quando ocorre a quebra da união no pomar ou viveiro. As classes A, B e C são consideradas compatíveis, pois não apresentam prejuízo à resistência mecânica da planta, entretanto, as classes D e E são incompatíveis, pois podem romper-se por dano mecânico ou ação do vento.

$\mathrm{O}$ segundo método, o índice de compatibilidade a campo (ICC), foi calculado de acordo com a fórmula desenvolvida por PERRAUDINE (1962): ICC $=[(\mathrm{C} / \mathrm{A})+(\mathrm{C}+\mathrm{A}) / 2 \mathrm{~B}] / 10$, em que A: indica o diâmetro da cultivar $(5 \mathrm{~cm}$ acima do ponto de enxertia); B: o diâmetro do ponto de união do enxerto; e C: o diâmetro do porta-enxerto $(5 \mathrm{~cm}$ abaixo do ponto de enxertia). Os diâmetros do caule foram mensurados com auxílio de um paquímetro 
digital, em setembro de 2009. Quanto maior o valor do ICC, maior a compatibilidade entre cultivar copa e porta-enxerto.

A avaliação do dano por bacteriose nas folhas foi estimada nas diferentes combinações de três formas. Primeiramente, em dezembro de 2009, uma amostra de cinquenta folhas, coletadas em cada parcela, foi classificada com base numa escala diagramática com diferentes níveis de dano, provocado pela doença. As cinco classes (Classe 1 ausência de doença, com $0 \%$ de dano na folha; Classe 2 - severidade baixa, com $<10 \%$ de dano na folha; Classe 3 - severidade regular, com $10-50 \%$ de dano na folha; Classe 4 - severidade alta, com 51-90\% de dano na folha; e Classe 5 - severidade extrema, com $>90 \%$ de dano na folha) foram pré-estabelecidas com auxílio do programa AFSoft (SILVA \& JORGE, 2009). Posteriormente, as mesmas folhas tiveram sua área $\left(\mathrm{cm}^{2}\right)$ mensurada com auxílio de um medidor de área foliar, modelo Area Meter 3100. Assim, foi possível identificar se a severidade da doença causou perda diferencial de tecido entre as oito combinações estudadas. Foi calculado, ainda, o índice de doença (\%), por meio de cinco escalas de notas: $0-0 \%$, $1-10 \%, 2-50 \%, 3-90 \%$ e $4-100 \%$ de dano. Para a determinação do índice de doença (variando de 0 $100 \%$ ), foi adaptada a seguinte equação (MORAES, 1999): Índice de doença $(\%)=\left(\mathrm{n}_{0} * 0+\mathrm{n}_{1} * 10+\mathrm{n}_{2} * 50\right.$ $\left.+\mathrm{n}_{3} * 90+\mathrm{n}_{4} * 100\right) / \mathrm{N}$, em que $\mathrm{n}_{0}, \mathrm{n}_{1}, \mathrm{n}_{2}, \mathrm{n}_{3}$ e $\mathrm{n}_{4}$ são o número de folhas da amostra com as notas $0,1,2,3 \mathrm{e}$ 4 e, $\mathrm{N}$ é o número total de folhas da amostra.

A avaliação de frutificação foi realizada através do número de frutos produzidos por planta, realizada após o período de raleio (diâmetro médio de $30 \mathrm{~mm}$ ), nas três plantas centrais de cada parcela. Visando estudar o efeito da incompatibilidade sobre o dano por bacteriose e o número de frutos produzidos, foi realizado um estudo de correlação entre o ICC e as variáveis, dano por bacteriose, em nível maior que $50 \%$ (soma do percentual correspondente às classes severidade alta e severidade extrema), área foliar e número de frutos. Os resultados foram submetidos à análise de variância $(\mathrm{P}<0,05)$ e as médias comparadas pelo teste de Tukey a $5 \%$ de probabilidade de erro.

\section{RESULTADOS E DISCUSSÃO}

A análise da anatomia da região de união das oito combinações estudadas apontou para incompatibilidade severa da classe Dentre 'Chimarrita' e 'Maciel' e o porta-enxerto 'Umezeiro' (Tabela 1), caracterizada pela descontinuidade vascular entre cultivar copa e porta-enxerto. Segundo MOSSE \&
HERRERO (1951), combinações desta classe podem romper-se com relativa facilidade. Este resultado repetiu-se na avaliação do ICC, que apresentou efeito isolado dos fatores cultivar e porta-enxerto e através do qual se verificou que o porta-enxerto 'Umezeiro' apresenta menor índice de compatibilidade a campo com as cultivares 'Chimarrita' e 'Maciel' (Tabela 1).

Os sintomas de incompatibilidade entre 'Umezeiro' e as cultivares testadas também foram observados visualmente no caule e através dos resultados de diâmetro do caule, sendo verificada interação significativa entre os fatores porta-enxerto e ponto de avaliação do diâmetro, assim como, entre cultivar e ponto de avaliação do diâmetro (Tabela 1). Na cultivar e no portaenxerto, o diâmetro foi menor nas combinações com 'Umezeiro'. Enquanto, no ponto de união do enxerto dessas combinações, o diâmetro foi igual e até superior às demais (Tabela 1). Em geral, os resultados obtidos pelo estudo de compatibilidade apresentaram as combinações envolvendo o portaenxerto 'Umezeiro', como tento elevado grau de incompatibilidade, corroborando com TELLES et al. (2009), COMIOTTO et al. (2012) e PEREIRA et al., (2014) que também observaram que o portaenxerto 'Umezeiro' é incompatível com inúmeras cultivares de pessegueiro, inclusive 'Chimarrita' e 'Maciel'. Esse fato pode estar relacionado à sua origem botânica, uma vez que as cultivares de pessegueiro pertencem à espécie $\boldsymbol{P}$. persica, enquanto que 'Umezeiro' à $\boldsymbol{P}$. mume.

Segundo CITADIN et al. (2008), a utilização da escala diagramática para avaliação da bacteriose em pessegueiro permite quantificar os sintomas da doença de forma acurada e precisa. Neste experimento, entre as combinações avaliadas com base na escala diagramática, não foram observadas folhas na Classe 1 , ausência de doença, resultado que indica ter havido alta incidência de bacteriose no pomar.

Em relação à infecção por bacteriose nas diferentes combinações testadas, houve efeito de interação entre os fatores cultivar, porta-enxerto e nível de dano por bacteriose (Figura 1A). Em geral, as combinações envolvendo a cultivar 'Chimarrita' sofreram menor dano pela infecção por bacteriose com relação às combinações com 'Maciel', sugerindo que a segunda pode ser mais suscetível à doença. Essa diferença de suscetibilidade entre cultivares de pessegueiro também foi verificada por MEDEIROS et al. (2011), que estudaram a suscetibilidade de diversas cultivares de pessegueiro a essa doença. Entre as combinações, 'Chimarrita'/'Aldrighi' foi menos 
Tabela 1 - Efeito dos fatores isolados, cultivar e porta-enxerto, sobre a classe de compatibilidade, o índice de compatibilidade a campo (ICC), o índice de doença, a área foliar e a frutificação, assim como o efeito de interação dos fatores cultivar e porta-enxerto com o ponto de avaliação do diâmetro do caule, nas combinações das cultivares de pessegueiro 'Chimarrita' e 'Maciel' com os portaenxertos 'Aldrighi', 'Capdeboscq', 'Tsukuba 1' e 'Umezeiro'. Pelotas, janeiro de 2015.

\begin{tabular}{|c|c|c|c|c|c|c|c|c|}
\hline \multirow{2}{*}{$\begin{array}{l}\text { Porta-enxerto/ } \\
\text { Cultivar }\end{array}$} & \multirow{2}{*}{$\begin{array}{c}\text { Classe de } \\
\text { compatibilidade }\end{array}$} & \multirow{2}{*}{$\mathrm{ICC}$} & \multicolumn{3}{|c|}{--------Diâmetro do caule $(\mathrm{cm})--------$} & \multirow{2}{*}{ Índice de doença (\%) } & \multirow{2}{*}{$\begin{array}{l}\text { Área foliar } \\
\quad\left(\mathrm{cm}^{2}\right)\end{array}$} & \multirow{2}{*}{$\begin{array}{c}\text { Frutificação } \\
\left(\text { frutos planta }^{-1}\right)\end{array}$} \\
\hline & & & Cultivar & União & Porta-enxerto & & & \\
\hline 'Aldrighi' & A & $10,41 \mathrm{a}^{*}$ & $26,50 \mathrm{a}$ & $33,43 \mathrm{a}$ & $28,78 \mathrm{a}$ & $45,85 \mathrm{~b}$ & $1637,88 \mathrm{a}$ & $37,10 \mathrm{a}$ \\
\hline 'Capdeboscq' & A & $10,42 \mathrm{a}$ & $24,80 \mathrm{a}$ & $31,10 \mathrm{~b}$ & $26,27 \mathrm{a}$ & $46,83 \mathrm{~b}$ & $1679,50 \mathrm{a}$ & $31,39 \mathrm{ab}$ \\
\hline 'Tsukuba 1' & A & $10,40 \mathrm{a}$ & $25,79 \mathrm{a}$ & $33,85 \mathrm{a}$ & $28,74 \mathrm{a}$ & $49,75 \mathrm{~b}$ & $1559,37 \mathrm{a}$ & $24,27 \quad b$ \\
\hline 'Umezeiro' & $\mathrm{D}$ & $10,32 \mathrm{~b}$ & $21,43 \mathrm{~b}$ & $34,71 \mathrm{a}$ & $22,28 \mathrm{~b}$ & $74,65 \mathrm{a}$ & $1253,87 \mathrm{~b}$ & $13,04 \mathrm{c}$ \\
\hline 'Chimarrita' & - & $10,39 \mathrm{a}$ & $23,24 \mathrm{a}$ & $31,74 \mathrm{a}$ & $26,06 \mathrm{a}$ & $48,05 \mathrm{~b}$ & $1687,06 \mathrm{a}$ & $31,63 \mathrm{a}$ \\
\hline 'Maciel' & - & $10,39 \mathrm{a}$ & $26,01 \quad b$ & $34,80 \quad b$ & $26,98 \mathrm{a}$ & $60,49 \mathrm{a}$ & $1378,25 \mathrm{~b}$ & $21,27 \quad b$ \\
\hline $\mathrm{CV}(\%)$ & - & 0,15 & & 7,75 & & 19,25 & 5,89 & 25,82 \\
\hline
\end{tabular}

* valores seguidos da mesma letra na coluna, de cada fator, não diferem significativamente pelo teste de Tukey a $5 \%$ de probabilidade de erro.

danificada pela bacteriose em relação às demais, com 94\% das folhas distribuídas nas Classes 2 e 3, com severidade baixa e regular, e não apresentando folhas na Classe 5, severidade extrema (Figura 1A). Na combinação 'Chimarrita'/'Capdeboscq', houve uma diminuição do percentual de folhas nas Classes 2 e 3 e um aumento nas classes de maior dano, Classes 4 e 5, em relação à 'Chimarrita'/'Aldrighi'. Distribuição similar foi observada em 'Chimarrita'/'Tsukuba 1', em que $79 \%$ das folhas foram distribuídas nas Classes 2 e 3 ; porém, com um incremento da Classe 4 . $\mathrm{Na}$ combinação 'Chimarrita'/'Umezeiro', anteriormente caracterizada como incompatível, houve incremento significativo das Classes 4 e 5, contrastando com uma diminuição importante da Classe 2.

Entre as combinações envolvendo a cultivar 'Maciel', 'Maciel'//Aldrighi' teve 5,5\% das folhas pertencendo à Classe $5,28 \%$ à Classe $4 \mathrm{e}$ apenas $15,5 \%$ à Classe 2 (Figura $1 \mathrm{~A}$ ). As combinações 'Maciel'/'Capdeboscq' e 'Maciel'/'Tsukuba 1' apresentaram comportamento similar em relação aos danos causados pela bacteriose nas folhas, com uma diferença importante em relação à Classe 5 , que foi de 1,5\% em 'Maciel'/'Capdeboscq', enquanto que em 'Maciel'/‘Tsukuba 1' não houve folhas nesta mesma classe. A combinação 'Maciel'/'Umezeiro' foi a mais danificada pela infecção por bacteriose entre todas as oito estudadas. Apresentou 22,5\% das folhas classificadas na Classe 5 e $53 \%$ na Classe 4 , ou seja, $75,5 \%$ das folhas estavam com mais de $50 \%$ de sua área comprometida pela doença. Além disso, a Classe 2 representou apenas $0,5 \%$ do total de folhas.
Para oíndice de doença, não houve interação significativa, apenas efeito isolado dos fatores cultivar e porta-enxerto (Tabela 1). Foi observado que, entre os porta-enxertos, 'Umezeiro' induz maior índice de doença às cultivares 'Chimarrita' e 'Maciel', cerca de $75 \%$, enquanto os demais não diferem entre si, apresentando índice inferior a 50\%. Já entre as cultivares, 'Maciel' apresentou um índice da doença de $60 \%$, sendo significativamente superior à 'Chimarrita', que teve um índice de 48\%. Resultados que corroboram com os apresentados anteriormente pelo estudo de distribuição de classes.

As avaliações da incidência de bacteriose mostraram que, nas combinações incompatíveis, 'Chimarrita'/‘Umezeiro' e 'Maciel'/'Umezeiro', incidência e a intensidade de dano foram significativamente superiores ao observado nas combinações compatíveis. Esses resultados sugerem que o fenômeno da incompatibilidade de enxertia, além de influenciar diretamente no crescimento das plantas, induz maior sensibilidade da cultivar 'copa' à bacteriose.

Tendo em vista os resultados da distribuição percentual das folhas entre as classes da escala diagramática, onde se constatou importante grau de severidade da doença em algumas combinações, foi realizada a mensuração da área foliar destas, visando a identificar uma possível diferença causada pela doença. Para este estudo, não foi verificado efeito de interação entre fatores, apenas efeito isolado dos fatores cultivar e porta-enxertos (Tabela 1), sendo observada menor área foliar nas combinações de 


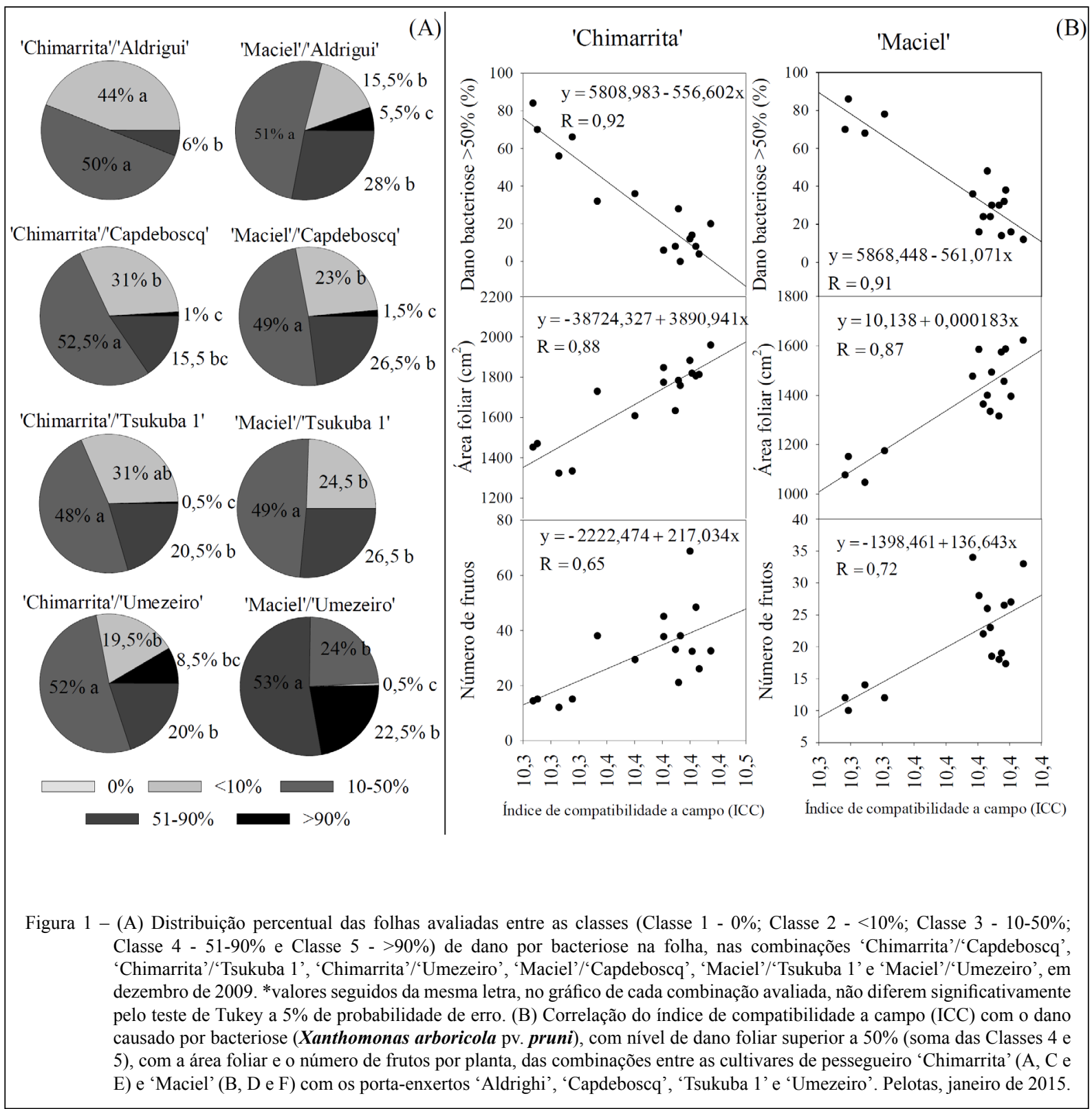

ambas as cultivares com o porta-enxerto 'Umezeiro', resultado que indica uma significativa perda de tecido foliar dessas combinações em relação às demais; perda de tecido que ocorre apenas em estádios avançados da doença (MAY DE MIO et al., 2004). Houve diferenças significativas também entre as cultivares, nas quais 'Maciel' teve menor área foliar que 'Chimarrita', característica que pode ser inerente à cultivar, mas que também pode ser atribuída à maior suscetibilidade à bacteriose apresentada por Maciel nos estudos de severidade e índice de doença.

Em relação à frutificação, não houve interação entre os fatores cultivar e porta-enxerto, apenas efeito isolado dos fatores cultivar e portaenxerto (Tabela 1). O porta-enxerto 'Aldrighi' proporcionou maior número de frutos, seguido de 'Capdeboscq' e 'Tsukuba 1'. Por outro lado, 'Umezeiro', caracterizado como incompatível, induziu o menor número de frutos. Em termos percentuais, o número de frutos obtidos em 'Chimarrita' e 'Maciel', enxertadas sobre 'Capdeboscq', 'Tsukuba 1' e 'Aldrighi', foi, respectivamente, $186 \%, 241 \%$ e $285 \%$ maior que o obtido quando as mesmas cultivares foram enxertadas sobre 'Umezeiro'. Já em relação às cultivares, 'Maciel' apresentou menor número de frutos que 'Chimarrita', resultado que pode estar 
atrelado ao fato de que aquela tenha se apresentado mais sensível aos danos por bacteriose.

Em todas as avaliações, as combinações que apresentaram os piores resultados foram as que anteriormente haviam sido caracterizadas como incompatíveis. Baseado nesta tendência foi realizado um estudo de correlação com o intuito de estabelecer uma possível relação entre a incompatibilidade de enxertia e o percentual de dano por bacteriose nas folhas, assim como, com a perda de área foliar e número de frutos das cultivares de pessegueiro utilizadas (Figura 1B). Para tal, foi utilizado o ICC, que apresentou o mesmo resultado da avaliação anatômica da união dos enxertos e identificou as combinações 'Chimarrita'/'Umezeiro' e 'Maciel'/‘Umezeiro' como tendo menor índice de compatibilidade.

Através dessa estratégia, foi observado um efeito altamente significativo $(\mathrm{P}=0,001)$ da compatibilidade de enxertia sobre o percentual de dano causado pela bacteriose nas folhas de 'Chimarrita' e 'Maciel', ou seja, quanto maior a compatibilidade menor foi o percentual de folhas com mais de $50 \%$ de sua área atacada pela doença (Figura 1B).

Em relação às variáveis, área foliar e número de frutos, a tendência foi oposta, havendo um comportamento positivo, no qual, quanto maior a compatibilidade, maior foi à área foliar e o número de frutos. Na cultivar 'Chimarrita', a correlação entre ICC e área foliar foi altamente significativa $(\mathrm{P}=0,001)$, com um coeficiente de correlação de $88 \%$ (Figura 1B). Resultado semelhante foi verificado nas combinações envolvendo a cultivar 'Maciel', com coeficiente de correlação significativo $(\mathrm{P}=0,001)$ de $87 \%$ (Figura $1 \mathrm{~B}$ ).

$\mathrm{Na}$ análise de correlação entre o ICC e o número de frutos, houve comportamento similar ao verificado com a área foliar, na qual, conforme se aumenta o ICC, ou seja, é maior a compatibilidade de enxertia, aumenta o número de frutos. Nas combinações com 'Chimarrita', a correlação entre ICC e número de frutos foi significativa $(\mathrm{P}=0,007)$ com coeficiente de $65 \%$ (Figura 1B). Já no caso das combinações com 'Maciel', a correlação também foi significativa $(\mathrm{P}=0,002)$, porém, com coeficiente maior, de 72\% (Figura 1B).

Segundo os resultados apresentados neste trabalho, a incompatibilidade de enxertia aumentou a intensidade de dano por bacteriose nas folhas e diminuiu a área foliar e o número de frutos. De acordo com NOCITO et al. (2010), a incompatibilidade de enxertia desencadeia uma situação de estresse oxidativo na planta, caracterizada pela produção excessiva de células reativas de oxigênio (ROS), como o peróxido de hidrogênio $\left(\mathrm{H}_{2} \mathrm{O}_{2}\right)$, o oxigênio singlet $\left({ }^{1} \mathrm{O}_{2}\right)$ e os radicais super óxidos $\left(\mathrm{O}_{2}^{-}\right)$e hidroxilas (HO). $\mathrm{O}$ estresse oxidativo ataca a estrutura das células, danificando proteínas, lipídios, carboidratos e o DNA, podendo provocar a morte destas (GILL \& TUTEJA, 2010). Esta reação da planta à incompatibilidade de enxertia também ocorre em relação a outras formas de estresse, tanto bióticos quanto abióticos, tais como, deficiência de nitrogênio, temperaturas extremas, estresse hídrico e radiação UV (ABOGADALLAH, 2011; RUBIO-WILHELMI et al., 2012; TERRA et al., 2012). Dessa forma, tudo indica que, nas combinações 'Chimarrita'/'Umezeiro' e 'Maciel'/'Umezeiro', o estresse gerado inicialmente pela incompatibilidade de enxertia condiciona a planta à situação de maior suscetibilidade à bacteriose, aumentando a intensidade do dano causado por essa doença. Além disso, a infecção por patógenos, tal qual a verificada neste experimento, também induz o aumento da produção de células reativas de oxigênio e consequentemente o estresse oxidativo (KUMAR \& ROBERTS 2011; CHEN et al., 2012). Dessa forma, pode estar havendo um estresse oxidativo de grandes proporções, uma vez que o estresse da incompatibilidade é potencializado pelo estresse causado pela infecção por bacteriose, condição que resulta no menor número de frutos produzidos por essas combinações.

\section{CONCLUSÃO}

Nas condições deste experimento, concluise que: a) as combinações 'Chimarrita'/'Umezeiro' e 'Maciel'/'Umezeiro' são incompatíveis, mais suscetíveis à bacteriose e apresentam menor frutificação em relação às combinações das cultivares 'Chimarrita' e 'Maciel' com os portaenxertos 'Aldrighi', 'Capdeboscq' e 'Tsukuba 1'; b) a incompatibilidade de enxertia induz maior suscetibilidade das plantas à infecção por Xanthomonas arboricola pv. pruni, resultando em maior severidade da doença e menor frutificação.

\section{AGRADECIMENTOS}

Os autores agradecem ao Conselho Nacional de Desenvolvimento Científico e Tecnológico (CNPq) e à Coordenação de Aperfeiçoamento de Pessoal de Nível Superior (CAPES), pelo apoio financeiro.

\section{REFERÊNCIAS}

ABOGADALLAH, G.M. Differential regulation of photorespiratory gene expression by moderate and severe salt and 
drought stress in relation to oxidative stress. Plant Science, v.180, n.3, p.540-547, 2011. Disponível em: <http://dx.doi.org/10.1016/j. plantsci.2010.12.004>. Acesso em: 15 jun. 2012. doi: 10.1016/j. plantsci.2010.12.004

CARLUCCI, A. et al. A study on the susceptibility to Eutypa armeniacae of various combinations of apricot cultivars and rootstocks. Acta Horticulturae, v.658, p.399-402, 2004.

CHEN, P-S. et al. Understanding cellular defence in kumquat and calamondin to citrus canker caused by Xanthomonas citri subsp. citri. Physiological and Molecular Plant Pathology, v.79, p.1-12, 2012.

CITADIN, I. et al. Escala diagramática para avaliação da severidade de bacteriose em pessegueiro. Revista Brasileira de Fruticultura, v.30, n.2, p.327-330, 2008. Disponível em: <http:// dx.doi.org/10.1590/S0100-29452008000200010>. Acesso em: 15 dez. 2011. doi: 10.1590/S0100-29452008000200010.

COMIOTTO, A. et al. Vigor, floração, produção e qualidade de pêssegos 'Chimarrita' e 'Maciel' em função de diferentes portaenxertos. Ciência Rural, v.42, n.5, p.788-794, 2012. Disponível em: $\quad<$ http://dx.doi.org/10.1590/S0103-84782012000500005>. Acesso em: 2 jul. 2012. doi: 10.1590/S0103-84782012000500005.

ERREA, P. Compatibilidad de injerto en albaricoquero ( $\boldsymbol{P}$. armeniaca). Anatomia y bioquímica de uniones compatibles e incompatibles. 1991. 233f. Tesis (Doctoral) - Universidad de Navarra. Navarra-España.

FACHINELLO, J.C. et al. Propagação de plantas frutíferas. Brasília: Embrapa Informação Tecnológica, 2005. 221p.

FORTES, J.F.; MARTINS, O.M. Sintomatologia e controle das principais doenças. In: MEDEIROS, C.A.B.; RASEIRA, M. do C.B. (Ed.). A cultura do pessegueiro. Pelotas: Embrapa CNPACT, 1998. p.243-264.

GILL, S.S.; TUTEJA, N. Reactive oxygen species and antioxidant machinery in abiotic stress tolerance in crop plants. Plant Physiology and Biochemistry, v.48, p.909-930, 2012. Disponível em: $<\mathrm{http} / /$ www.sciencedirect.com/science/article/pii/ S0981942810001798>. Acesso em: 25 jun. 2012. doi: 10.1016/j. plaphy.2010.08.016.

HARTMANN, H.T. et al. Plant propagation. Principles and practices. 7.ed. Upper Saddle River, NJ: Prentice-Hall, 2002. p.411-460.

KUMAR, N. et al. $\mathrm{H}_{2} \mathrm{O}_{2}$ degradation is suppressed in kumquat leaves infected with Xanthomonas axonopodis pv. Citri. Scientia Horticulturae, v.130, n.1, 26, p.241-247, 2011.

LOUWS, F.J. et al. Grafting fruiting vegetables to manage soilborne pathogens, foliar pathogens, arthropods and weeds. Scientia Horticulturae, v.127, n.2, p.27-146, 2010
MAY DE MIO, L.L. et al. Doenças de fruteiras de caroço. In: MONTEIRO, L.B.; MAY DE MIO, L.L. (Ed.). Fruteiras de caroço: uma visão ecológica. Curitiba: Universidade Federal do Paraná, 2004. p.169-222.

MEDEIROS, J.G.S. et al. Reaction of peach tree genotypes to bacterial leaf spot caused by Xanthomonas arboricola pv. Pruni. Scientia Agricola, v.68, n.1, p.57-61, 2011. Disponível em: $<$ http://dx.doi.org/10.1590/S0103-90162011000100009>. Acesso em: 25 jun. 2012.

MORAES, S.A. Monitoramento das doenças foliares do amendoim e avisos climáticos para indicar as pulverizações com fungicidas. O Agronômico, v.51, n.2-3, p.86-89, 1999.

MOSSE, B. Further observation on growth and union structure of double grafted pear on quince. Journal of Horticultural Science, v.33, p.186-193, 1958.

MOSSE, B.; HERRERO, J. Studies on incompatibility between some pear and quince grafts. Journal of Horticultural Science, v.26, p.238-245, 1951.

NOCITO, F.F. et al. Oxidative stress and senescence-like status of pear calli co-cultured on suspensions of incompatible quince microcalli. Tree Physiology, v.30, p.450-458, 2010. Disponível em: <http://treephys.oxfordjournals.org/ content/30/4/450.full.pdf + html $>$. Acesso em: 05 jun. 2012. doi: $10.1093 /$ treephys/tpq006.

PEREIRA, I.S. et al. Growth characteristics and phenylalanine ammonia-lyase activity in peach grafted on different Prunus spp. Biologia Plantarum, v.58, n.1, p.114-120, 2014. Disponível em: $<$ http://link.springer.com/article/10.1007\%2Fs 10535 013-0370-9\#page-1>. Acesso em: 05 jul. 2014. doi: 10.1007/ s10535-013-0370-9.

PERRAUDI. La Pomologie Françoise. Fevrier, 1962. N.2.

RUBIO-WILHELMI, M.M. et al. Effect of cytokinins on oxidative stress in tobacco plants under nitrogen deficiency. Environmental and Experimental Botany, v.72, n.2, p167173, 2011.

SILVA, D.J.C.B.; JORGE, L.A.C. AFSoft ${ }^{\circledR}$ - Software para análise foliar. São Carlos, SP: Embrapa Instrumentação Agropecuária, 2009. $20 \mathrm{p}$

TELLES, C.A. et al. Fenóis totais, peroxidase e suas relações com a compatibilidade de mudas de pessegueiro interenxertadas. Ciência e Agrotecnologia, v.33, p.86-91, 2009.

TERRA, V.A. et al. Time-dependent reactive species formation and oxidative stress damage in the skin after UVB irradiation. Journal of Photochemistry and Photobiology B: Biology. v.109, n.2, p.34-41, 2012. 